\title{
TRANSGRESSION SEVERITY AND FORGIVENESS: DIFFERENT MODERATORS FOR OBJECTIVE AND SUBJECTIVE SEVERITY
}

\author{
FRANK D. FINCHAM \\ Florida State University \\ HOPE JACKSON AND STEVEN R.H. BEACH \\ University of Georgia
}

The current investigation examines insider/subjective and outsider/objective perspectives on forgiveness. Two hundred and thirty-two undergraduates in dating relationships were asked to describe situations in which they had been hurt by their romantic partners. Both subjective and objective ratings of event severity predicted forgiveness. In addition, rejection sensitivity proved consequential in moderating the impact of objective severity whereas responsibility attributions moderated the impact of subjective severity ratings. These results suggest the need to adopt a more complex model of forgiveness, and that as researchers develop increasingly sophisticated interventions to promote forgiveness, it will be important to consider both objective and subjective influences.

The study of forgiveness has recently captured the attention of psychologists (for an overview see McCullough, Pargament, \& Thoresen, 2000). This increased interest reflects recognition that forgiveness represents an important response to a fundamental human challenge-how to maintain relatedness with fellow humans in the face of being harmed by them. It is a rare person who does not, at some point, feel hurt, let down, betrayed, disappointed or wronged by another human. When interpersonal transgressions occur they can elicit strong negative feelings. McCullough, Worthington, and Rachal (1997) posit that these affective responses occur along two continua; one reflects emotions related to righteous indignation (e.g., sadness, anger, and contempt), whereas the

Correspondence concerning this article should be addressed to Frank Fincham, Family Institute, Sandels Building, Florida State University, Tallahassee, FL 32306-1491; E-mail: ffincham@fsu.edu. 
other dimension captures emotions related to hurt and perceived attack (e.g., fear and worry). These affective responses, in turn, prompt revenge and avoidance, respectively. Thus transgressions can disrupt the relationship between the transgressor and the victim and they therefore pose a significant challenge to ongoing intimate relationships. How partners respond to transgressions may affect the way in which they behave toward the offender in future interactions. Perhaps not surprisingly, spouses report that the capacity to seek and grant forgiveness is one of the most important factors contributing to marital longevity and marital satisfaction (Fenell, 1993).

Despite its importance for intimate relationships, our knowledge of forgiveness in this context remains rudimentary. It has become clear that relationship variables are related to forgiveness, including commitment (Finkel, Rusbult, Kumashiro, \& Hannon, 2002), closeness (McCullough et al., 1998), and relationship satisfaction (Fincham \& Beach, 2002a; Fincham, Paleari, \& Regalia, 2002). Also, as in the broader literature on forgiveness (e.g., Darby \& Schlenker, 1982), the severity of partner transgressions is linked to partner forgiveness with more severe transgressions being associated with less forgiveness (e.g., Boon \& Sulsky, 1997). Indeed, the relationship between transgression severity and forgiveness is arguably the most robust phenomenon in the forgiveness literature. Perhaps because it is so widely accepted, there has been little analysis of this association. Does it hold regardless of the perspective from which transgression severity is viewed? And what are the boundary conditions under which this relationship holds? The present study addresses these questions.

Psychologists have adopted two different perspectives in studying constructs. The first is the perspective of the participant, or the subjective perspective, and the second is that of the observer/scientist, or objective perspective. This is evident, for example, in attribution research where scientists have determined, on an a priori basis, the extent to which causes for failure reflect particular underlying dimensions (e.g., Weiner et al., 1971) and have studied how these "objectively" classified causes predict other variables (e.g., subsequent behavior). But attribution researchers have also asked participants themselves to rate directly the underlying dimensions of causes (e.g., Buchanan \& Seligman, 1995) and have used this subjective perspective to predict other variables. Neither perspective represents "truth"; rather they represent complementary perspectives on the phenomena studied. In an analogous manner, complementary perspectives are found in relationship research where the subjective perspective of the participant and the objective perspective of the observer are studied and are labeled insider and outsider perspectives, respectively (Olson, 1977). 
In the forgiveness literature transgression severity is most often rated by the research participant (e.g., Boon \& Sulsky, 1997). Where severity is objectively defined, it is usually limited to analogue studies where participants respond to hypothetical vignettes that present mild and severe transgressions (e.g., Darby \& Schlenker, 1982). To our knowledge, no study has investigated forgiveness using both subjective and objective measures of transgression severity to determine whether forgiveness relates to transgression severity in the same way from both perspectives. The present study examines this issue. Inclusion of both subjective and objective perspectives of transgression severity also allows the relations between them to be examined. This is important because victims have access to information (e.g., relationship history) that is not available to objective observers and this is likely to influence the experienced severity of the transgression. It is therefore hypothesized that the perspectives will be positively, but only moderately, correlated. Furthermore, it might be expected that objective severity influences subjective severity which, in turn, influences forgiveness. Stated differently, subjective severity is likely to mediate the relation between objective severity and forgiveness.

As regards boundary conditions for the transgression severity-forgiveness association, a number of variables have been related to forgiveness, ranging from personality traits, through social-cognitive processes of the victim, to events following the transgression. For example, the personality trait of agreeableness (Ashton, Paunonen, Helmes \& Jackson, 1998; McCullough, Bellah, Kilpatrick, \& Johnson, 2001) and the attributions made for the transgression and empathy are related to forgiveness (e.g., Bies \& Tripp, 1996; Boon \& Sulsky, 1997; Fincham, 2000; McCullough et al., 1997, 1998), while confessions and apologies accompanied by visible signs of contrition following the transgression foster forgiveness (Darby \& Schlenker, 1982; McCullough et al., 1997; Ohbuchi, Kameda \& Agarie, 1989; Weiner, Graham, Peter, \& Zmuidinas, 1991). It appears, however, that while a number of factors may foster forgiveness little is known about the boundary conditions under which they operate and none of them have been investigated as potential moderators of forgiveness. In the present study we therefore examine two variables as potential moderators of the transgression severity-forgiveness association.

The first variable investigated is the victim's attributions or explanations for the transgression. Forgiveness is inversely related to the tendency to make conflict promoting attributions for negative partner behavior; that is, to see the behavior as intentional, selfishly motivated, and blameworthy (Fincham, 2000). Compared to low levels, high levels of this pattern of responsibility attribution may accentuate the perceived 
impact and the perceived long-term threat implied by the transgression and make forgiveness correspondingly more difficult. If so, attributions should moderate the association between perceived outcome severity and forgiveness such that a stronger relationship should be found at high versus low levels of conflict promoting attributions.

The second potential moderating variable investigated, rejection sensitivity, is not one that has received empirical attention in the forgiveness literature. This is an important oversight because in the context of an ongoing relationship, transgressions can be viewed as a powerful symbolic sign of rejection by the transgressor. Rejection sensitivity is the tendency to anxiously or angrily expect, readily perceive, and overreact to rejection (Downey \& Feldman, 1996). Transgressions that may require forgiveness against those who are sensitive to rejection are likely to be interpreted as signs of rejection and as an indication that the transgressor devalues the relationship, or at least does not value the relationship as much as the victim desires (Leary, 2001). Because the rejection-sensitive individual is likely to interpret the transgression in this manner, the transgression may prompt significant anxiety about the potential loss of the relationship and emotional overreactions (Downey, Bonica, \& Rincon, 1999), and any motivation to forgive is likely to be based on this fear. There is, however, evidence that rejection sensitive individuals show maladaptive responses to rejection in the form of hostility, jealousy, and abusiveness (Ayduk, Downey, Testa, Yen, \& Shoda, 1999; Downey, Feldman, \& Ayduk, 2000) and, not surprisingly, rejection sensitivity has been linked to poor outcomes in a variety of realms, including interpersonal difficulties (Levy, Ayduk, \& Downey, 2001).

Downey et al. (1999) have posited that the rejection-sensitive individual may react with coercion, becoming angry, sullen, or violent (e.g., only holding out forgiveness in order to make the partner feel guilty or fearful of what would happen if they ended the relationship). Or, the rejection-sensitive individual may react with compliance, attempting to cause the perpetrator to see him or her in a positive light and decrease any potential for the perpetrator to end the relationship (e.g., offer forgiveness that is based more on ensuring that the rejection does not lead to the end of the relationship, rather than any acknowledgment of hurt or justification to act negatively toward the perpetrator). In light of these observations it is unclear whether rejection sensitivity will be related to tendencies toward forgiveness overall, but it may nonetheless moderate the relation between transgression severity and forgiveness. Specifically, it can be hypothesized that at high levels of rejection sensitivity the individual will be so pre-occupied with the symbolic significance of the rejection that no relation between objective transgression severity and 
forgiveness will be found, a circumstance which should not hold for low rejection sensitive individuals.

In sum the present study investigated the following hypotheses.

Hypothesis 1: Ease of forgiveness will be related to objective and subjective indices of transgression severity.

Hypothesis 2: Subjective and objective indices of transgression severity will be positively but only moderately correlated.

Hypothesis 3: The subjective impact of the event will mediate the relationship between objective severity and ease of forgiveness.

Hypothesis 4: Attributions for the transgression will be related to ease of forgiveness. Specifically, attributions for the transgression that infer negative intent, selfishness and blameworthiness will be negatively related to the expectation of forgiveness.

Hypothesis 5: Attributions for the transgression will moderate the relation between the perceived severity of the transgression and ease of forgiveness such that a stronger severity-forgiveness relation will be found for those showing a conflict promoting attribution style.

Hypothesis 6. Rejection sensitivity will moderate the relation between the perceived severity of the transgression and ease of forgiveness. Specially, the relation between transgression severity and ease of forgiveness will be found for those low in rejection sensitivity but not those high in rejection sensitivity.

\section{METHOD}

\section{PARTICIPANTS}

Participants ( $N=232 ; 63$ males and 172 females) were undergraduates recruited from a large southeastern university who were in a dating relationship of at least 3 months at the time of the study. A 3-month long relationship was required to allow time for relevant relationship issues to emerge and to allow dating partners to develop interdependence and some sense of couple identity. They had been dating their current partner on average between 12 and 24 months, with a range from 3 months to over 36 months and reported viewing the relationship as exclusive. Participants were given course credit for their participation. Sixty-two percent of the participants were between 17 and 19 years of age, 35\% were between 20 and 22 years, and the remainder of the sample was above 22 years of age. Twenty-eight percent of the sample had been in college 3 or more years. The group was predominately White (88\%), with 7\% African American, 1\% Hispanic, and 2\% Asian. As regards religious affilia- 
tion, $57 \%$ of participants were Protestant, $15 \%$ Catholic, 3\% Jewish, and $.4 \%$ Islamic; $15 \%$ opted for the category "other" while $10 \%$ chose "none."

\section{MEASURES}

Rejection Sensitivity. Anxious expectation of rejection, or rejection sensitivity was assessed using a questionnaire developed by Downey and Feldman (1996). It consists of 18 hypothetical situations involving parents, peers, and romantic partner, in which acceptance or rejection are possible outcomes. Participants respond along two dimensions: degree of anxiety about the outcome and expectations of acceptance or rejection. A Likert-type scale is used for both dimensions, with 1 representing the lowest degree of anxiety and least likelihood of acceptance and 6 representing the maximum degree of anxiety and greatest expectation of acceptance. Scoring involves weighting the expected likelihood of acceptance/rejection by degree of anxiety over its occurrence. The measure demonstrated high internal reliability (.83) and test-retest reliability ( 3 weeks $=.83 ; 4$ months $=.78$ ). Coefficient alpha in the present sample was .84 .

Transgression: Severity, Attributions, and Forgiveness. To assess forgiveness participants were asked to "recall a time when you felt hurt by something your partner did." They were given a blank sheet of paper and asked to provide a written description of the recalled situation. This helped to facilitate recall of the situation and also provided material for coding the severity of the transgression.

Both subjective and objective ratings were made of the severity of partner behavior. When they completed the description of the transgression participants indicated how hurt they were by the transgression, on a 10-point scale anchored by the descriptors not hurt at all and extremely hurt at each end. Higher scores indicated greater hurt. This served as a subjective measure of transgression severity. An objective measure of severity was obtained by coding the written description of the event. Two coders rated the severity of the event from the perspective of the "average person" in an attempt to avoid idiosyncratic inferences of severity. Coders were instructed to ignore information about the impact of the event on the participant and independently rated each transgression on the same 10-point scale used by participants. The Spearman-Brown formula for calculating effective reliability was used to assess inter-rater reliability, following Rosenthal's (1982) recommendation. Effective inter-rater reliability for event severity was calculated on a randomly selected $33 \%$ of the total usable sample. Severity ratings of the two coders were correlated (.63), resulting in an effective reliability (the reliability of the mean of the two judges' ratings rather than a single judge) of .79. 
After indicating how hurt they were by the partner's behavior participants then rated the extent to which they disagreed or agreed with several statements on a 6-point scale ranging from disagree strongly to agree strongly. Three of the statements assessed attributions for the transgression and four of the statements assessed forgiveness. The attribution questions were identical to those used in the Relationship Attribution Measure (Fincham \& Bradbury, 1992) to assess responsibility for partner behavior. Hence they inquired about the intent and motivation behind the partner's behavior and its blameworthiness. The three responses were summed to form an index of responsibility attribution with higher scores indicating more conflict promoting attributions (greater intent, selfish motivation, and partner blameworthiness). Coefficient alpha for this measure was .66 .

Four questions were used to assess ease of forgiveness: How easy was it to get over feeling negative or resentful for how you were mistreated? How difficult was it to think of your partner in a positive way again after this happened? How easy was it to feel warmly again towards your partner? To what extent were you able to forgive your partner? Participants indicated their answers on a 6-point scale ranging from impossible to very easy. Answers to the questions were summed to yield a highly reliable index of forgiveness (coefficient alpha $=.85$ ).

\section{PROCEDURE}

Participants were recruited in groups of 20. They first read and signed consent forms, and then the experimenter briefly described the nature of the study, discussed the instructions, and fielded questions. Participants were assured that their responses were confidential, and that their participation was voluntary. As part of a larger study, they then completed a demographics questionnaire, the Rejection Sensitivity Questionnaire (RSQ), and the assessment of forgiveness. The forgiveness assessment always followed the RSQ so that recall of a negative relationship event did not prime participants' responses to the RSQ. Upon completion of the study participants were fully debriefed by the experimenter and given forms explaining the nature and purpose of the study. Referrals were provided for all participants in case anyone might have experienced discomfort during the study.

\section{RESULTS}

Hypothesis 1: Ease of forgiveness will be related to objective and subjective indices of transgression severity.

The correlations among the variables are shown in Table 1. As ex- 
TABLE 1. Correlations Among the Variables Studied

\begin{tabular}{lrrrrrrr}
\hline & $\mathbf{1}$ & $\mathbf{2}$ & $\mathbf{3}$ & $\mathbf{4}$ & $\mathbf{5}$ & $\mathbf{M}$ & $\mathbf{S D}$ \\
\hline 1. Forgiveness & & -.49 & -.30 & -.35 & -.07 & 19.24 & 4.22 \\
2. Attributions & & & .28 & .27 & .01 & 10.36 & 3.20 \\
3. Subjective severity & & & & .49 & .09 & 7.47 & 1.98 \\
4. Objective severity & & & & & .11 & 4.46 & 1.58 \\
5. Rejection sensitivity & & & & & & 8.49 & 2.70 \\
& & & & & & \\
\hline
\end{tabular}

pected, forgiveness was related to subjective and objective transgression severity supporting our first hypothesis.

Hypothesis 2: Subjective and objective indices of transgression severity will be positively correlated.

Our second hypothesis, that subjective and objective indices of transgression severity will be positively, but only moderately correlated, was also supported. It appears that the two measures of transgression severity share only about $25 \%$ of their variance.

Hypothesis 3: The subjective impact of the event will mediate the relationship between objective severity and ease of forgiveness.

To address this question both subjective and objective measures of transgression severity served as predictor variables in a regression equation in which forgiveness was the dependent variable. In view of the above finding, it is perhaps not surprising that subjective severity $(\beta=-.37, p<.01)$ and objective severity $(\beta=-.69, p<.05)$ each made unique contributions to the prediction of forgiveness thus ruling out subjective severity as a full mediator of the association between objective severity and forgiveness. However, using the Delta Method (Sobel, 1988), we found that subjective transgression severity partially mediated the relationship between objective severity and forgiveness (indirect effects $=.23, p<.05$ ) providing some, though not complete support, for Hypothesis 3.

Hypothesis 4: Attributions for the transgression will be related to ease of forgiveness.

Hypothesis 4 predicted that attributions for the transgression that infer negative intent, selfishness, and blameworthiness will be negatively related to the expectation of forgiveness. As shown in Table 1, this hypothesis was supported. 
Hypothesis 5: Attributions for the transgression will moderate the relation between the perceived severity of the transgression and ease of forgiveness

The first step involved in examining Hypothesis 5 involved dealing with possible multicollinearity in predicting ease of forgiveness from attributions, transgression severity, and the interaction of these two variables. Accordingly, both the severity and attribution measures were centered before conducting the regression analyses (Aiken \& West, 1991). In the regression analyses, the centered severity and attribution variables were entered at Step 1 , followed by the product term (severity $\times$ attribution) at Step 2 . Two regression equations were computed that used the subjective and objective indices of severity, respectively. The attribution-severity product term was significant $(\beta=-.19, p<.01)$ when the subjective index of transgression severity was used, indicating that attributions do moderate the relationship between subjective severity and ease of forgiveness.

While significant moderation indicates that the slopes of the regression lines for the two predictors are significantly different, it is necessary to examine whether each slope differs from zero, and the way in which they differ from each other. Analysis of the moderating effect was conducted following the recommendations of Aiken and West (1991). Thus, the parameter estimates of subjective severity at one standard deviation above and one standard deviation below the mean for the attribution measure were examined. The simple slope of the subjective severity-forgiveness association at high levels of conflict promoting attributions was significantly different from zero $(\beta=-.66, p<.01)$. However, the simple slope of subjective severity at low levels of attribution did not differ from zero $(\beta$ $=-.02, p>.05$ ). These slopes are plotted in Figure 1. As can be seen, the effect of subjective severity on ease of forgiveness for individuals who make high levels of conflict promoting attributions is much stronger than its impact for individuals who make relatively fewer conflict promoting attributions. In sum, support was obtained for Hypothesis 5.

Hypothesis 6. Rejection sensitivity will moderate the relation between the perceived severity of the transgression and ease of forgiveness.

Hypothesis 6 was examined in the same manner as Hypothesis 5. Thus, ease of forgiveness was regressed onto the centered severity and rejection sensitivity variables and their product. The product term was significant $(\beta=-.16, p<.01)$ in the equation involving the objective index of transgression severity, indicating that rejection 


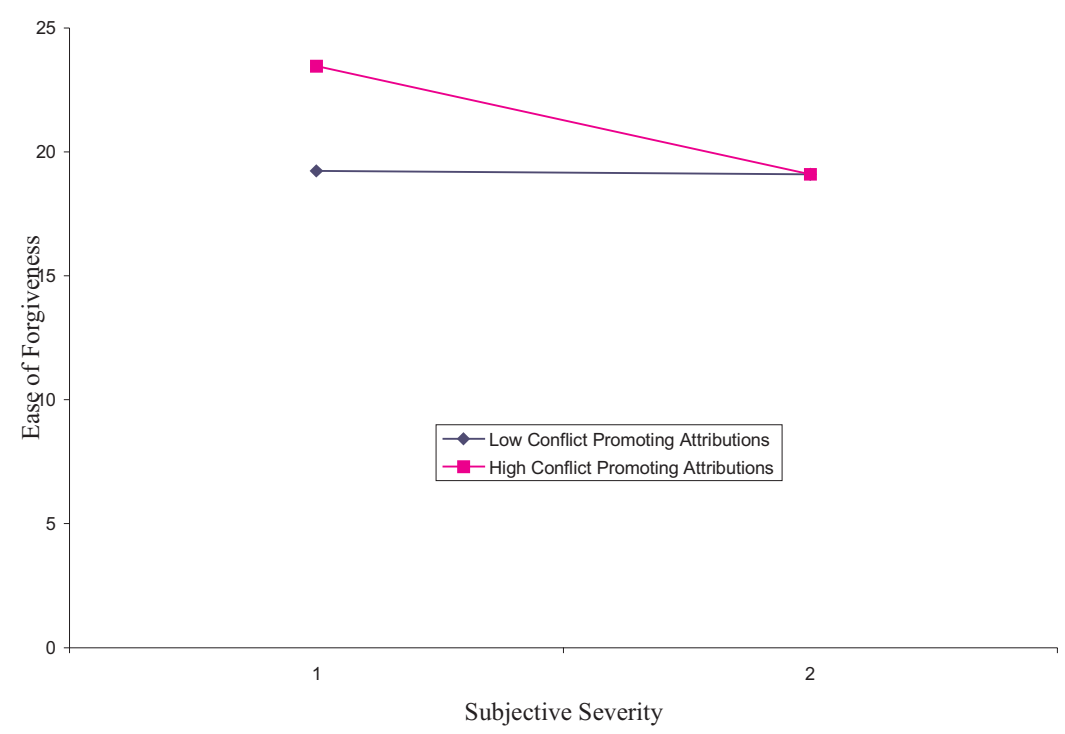

FIGURE 1. Simple slopes for high and low levels of conflict promoting attributions.

sensitivity moderates the relationship between observer coded transgression severity and ease of forgiveness. Further analysis revealed that the simple slope of the objective severity-forgiveness association at high levels of rejection sensitivity did not differ from zero $(\beta=-.14, p>$.05). Thus, for individuals high in rejection sensitivity, transgression severity did not affect ease of forgiveness. In contrast, increasing levels of transgression severity made it more difficult to forgive among individuals with low levels of rejection sensitivity $(\beta=-.51, p<.01)$. The slopes for high and low rejection sensitivity are plotted in Figure 2.

\section{DISCUSSION}

Previous research on forgiveness and the severity of partner transgressions has focused on transgression severity as rated by the victim (e.g., Fincham, 2000). A long history of research in psychology (cf. Olsen, 1977) suggests, however, that insider and outsider perspectives may yield different information. The current study therefore examined insider and outsider perspectives on severity of partner transgressions 


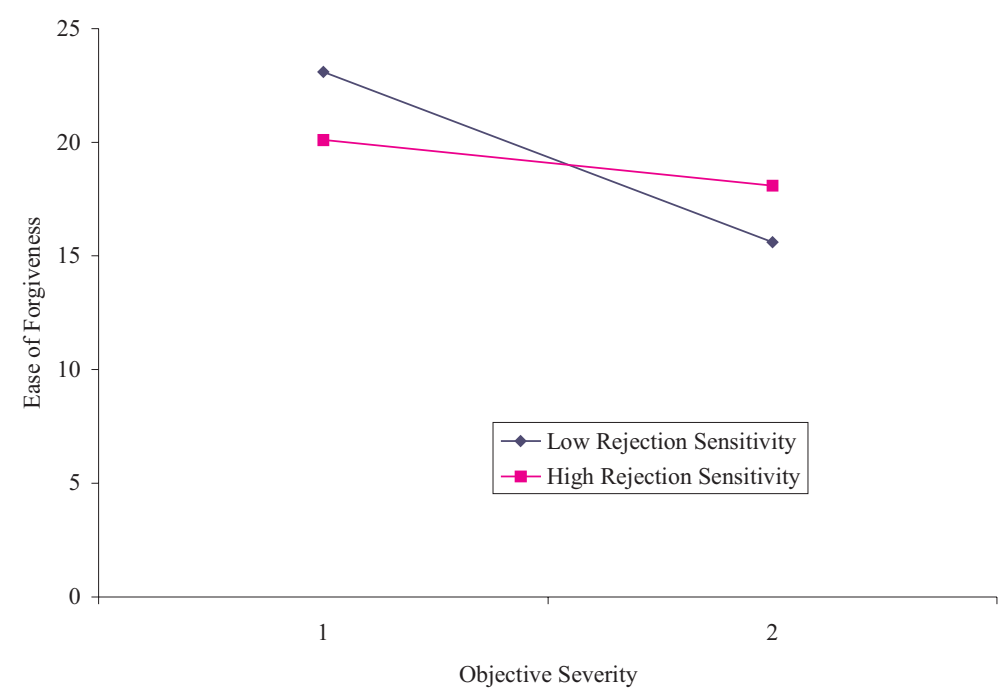

FIGURE 2. Simple slops for high and low levels of rejection sensitivity.

and the consequences of transgression severity for forgiveness. As expected, both insider and outsider perspectives proved to be important in accounting for forgiveness. In addition, they shared only about $25 \%$ of their variance, suggesting the potential for considerable divergence both in their relationship to forgiveness and in the factors that provide boundary conditions for their influence. Of particular importance for models of forgiveness, subjective severity only partially mediated the effect of objective severity on forgiveness. Accordingly, both objective and subjective severity may need to be included in models of forgiveness if we are to adequately capture responses to partner transgressions.

It is, perhaps, not surprising that both objective and subjective severity proved consequential for forgiveness. Objective severity, with its implications of lasting harm, public humiliation, erosion of trust, and involvement of a wider range of significant others, provides a potential range of cues that may influence forgiveness in spite of, or in addition to, the effect of subjective reactions. In contrast, subjective severity, with its implications of emotional dysregulation and subjective pain implicates the functioning of various self-process including self-soothing, self-regulation and self-evaluation maintenance. As a result, objective severity is likely to be most consequential in delaying or reducing forgiveness for 
those who are more focused on the tangible consequences of partner behavior. It is likely to be least consequential for those who may be focused instead on the "symbolic value," or the potential threat the partner transgression holds for the relationship. Conversely, subjective severity is likely to be most consequential for those whose interpretation of the partner behavior makes it difficult to recapture a benign view of the partner and least consequential for those whose interpretation of partner behavior suggests that the transgression was an aberration unlikely to be repeated. This may be why attributions (e.g., Fincham, 2000) and confessions or apologies (e.g., McCullough et al., 1997) have been found to play an important role in accounting for forgiveness in prior research. In previous research, the focus has been on understanding the impact of subjective severity. Accordingly, negative attributions may have emerged as particularly consequential in accounting for forgiving subjectively hurtful behavior because that subjectively hurtful behavior is expected to continue and is seen as having few mitigating factors.

In keeping with the different characteristics of objective and subjective severity, we found that objective and subjective severity were moderated by different variables. For objective severity, level of rejection sensitivity moderated the association with forgiveness. Only those low in rejection sensitivity showed an effect of increasing severity on forgiveness. For those high in rejection sensitivity, objective severity was unrelated to greater difficulty in forgiving. This is consistent with the view that persons focused on the "symbolic" or "threat" value of a partner transgression may be less influenced by the "real world" consequences of partner behavior. From the standpoint of symbolic threat, all partner transgressions, regardless of objective severity, may seem equally problematic and equally hard to forgive. That is, if attention is tightly focused on the rejection one has experienced by the partner, this may dominate the forgiveness process and leave little cognitive capacity for considerations of objective severity and tangible consequences of the transgression.

An alternative, albeit less parsimonious, explanation based on attachment considerations is that those high in rejection sensitivity may characteristically display increased protest in response to relatively minor partner transgressions in order to be sure of focusing partner attention on the problem. Difficulty in forgiving small transgressions could be a consequence of this attempt to increase partner attention to the transgression. Accordingly, minor transgressions may prove harder to forgive for those high in rejection sensitivity. But what of the more serious transgressions? From an attachment perspective, one might anticipate that serious partner transgressions might lead to avoidance of the threatening implications and efforts to quickly gain reassurance that the relationship is, in fact, intact and that the partner is not leaving the relation- 
ship. Thus, at high objective severity the rejection sensitive individual may once again fail to process the tangible consequences of the partner transgressions and rush to forgiveness as a way of minimizing the perceived relationship threat.

For subjective severity, attributions moderated the effect on forgiveness. As would be expected on the basis of prior research (e.g., Fincham, 2000), the more benign the attributions for the partner transgression the less the effect of subjective severity on forgiveness. So, regardless of how trivial or extreme their subjective rating of the severity of the partner transgression, those making benign attributions found it relatively easy, on average, to forgive. In this case, subjective severity of the partner transgression was not significantly related to forgiveness. Conversely, for those making non-benign, or conflict promoting, attributions suggesting that partners intended the negative outcome, were selfishly motivated, and that their behavior was blameworthy, subjective severity exerted a significant effect on forgiveness. The more severe the subjective impact, the harder it was to forgive the partner. Alternatively put, conflict promoting responsibility attributions appeared to potentiate the effect of relationship transgressions and render them more toxic. This suggests that those making benign attributions for a partner transgression were able to overcome their initial dysregulation, regardless of its intensity, and reach out more constructively to partners. Conversely, those making less benign attributions found it more difficult to overcome their dysregulation, and the more intense the initial dysregulation, the more difficult it was to reach out constructively to the partner in the spirit of forgiveness.

The present findings have important implications for interventions aimed at facilitating forgiveness between partners (Fincham \& Beach, $2002 b$ ). First, the current study suggests that interventions which can reduce conflict promoting responsibility attributions should be effective in reducing the effect of subjective but not objective severity. That is, interventions that help partners come to a different understanding of each other whether by going through corrective emotional experiences with the partner (Johnson, 2000), increased acceptance (Jacobson \& Christensen, 1998 ), or systematic reappraisal (Epstein \& Baucom, 2002), may all be useful in decreasing the extent to which intense subjective reactions to partner behavior lock the partners into unforgiveness. Any progress in re-attributing the partner's behaviors to less intentional, less selfish, and less blameworthy causes is likely to facilitate movement toward forgiving the partner. Conversely, work on decreasing conflict promoting responsibility attributions should be less effective in reducing the effect of objective severity. For partners who are focused on objectively severe partner transgressions (e.g., activities such as affairs or public humiliation that would tend to have a greater impact on the aver- 
age respondent), therapeutic efforts may need to focus on helping partners find ways to mitigate the harm created by the partner behavior before any progress can be made toward forgiveness. It is important, however, to note that not all transgressions are objectively severe. For those who are not focused on objectively severe partner transgressions, it may be important to focus first on the symbolic importance of the partner transgression. In particular, for those who are high in rejection sensitivity, a focus on the objective consequences of the partner transgression may have little effect on the way in which they respond or on the ease with which they are able to forgive.

The current study has several limitations. In particular, because the participants were in dating relationships it will be important to replicate conceptually similar patterns in married dyads. Likewise, because reports were retrospective, all partners had remained in their relationships despite the partner transgression they reported. Accordingly, the current study is unlikely to capture the processes that unfold when partner transgressions lead to relationship dissolution. Prospective longitudinal research is needed to capture such processes. Finally, because both subjective and objective severity were examined as between subject predictors, the current study does not address the question of whether within person shifts in perception of severity or in the moderators of severity would result in more or less forgiveness. This calls for a within subject examination across a range of conditions.

It appears that our models of forgiveness must become more complex. The variable of transgression severity needs to be considered from both an insider as well as an outsider perspective if we are to account for variance in forgiveness and to better understand the boundary conditions that govern the highly replicable connection between transgression severity and forgiveness. The model that emerges from the current investigation indicates that subjective severity is moderated by attributions for the partner behavior with distressing behavior being relatively easily forgiven if partner attributions are benign. Conversely, objective severity is moderated by rejection sensitivity, with relatively mild and relatively severe transgressions being equally difficult or easy to forgive for those who are high in rejection sensitivity. If replicated in future research, the basic model appears to hold important implications for both future research and for future efforts to enhance forgiveness interventions. 


\section{REFERENCES}

Aiken, L.S., \& West, S.G. (1991). Multiple regression: Testing and interpreting interactions. London: Sage.

Ashton, M.C., Paunonen, S.V., Helmes, E., \& Jackson, D.N. (1998). Kin altruism, reciprocal altruism, and the Big Five personality factors. Evolution and Human Behavior, 19, 243-255.

Ayduk, O., Downey, G., Testa, A., Yen, Y., \& Shoda, Y. (1999). Does rejection elicit hostility in rejection-sensitive women? Social Cognition, 17, 245-271.

Bies, R.J. \& Tripp, T.M. (1996). Beyond distrust: “Getting even” and the need for revenge. In R.M. Kramer \& T.R. Tyler (Eds.), Trust in organizations: Frontiers in theory and research (pp. 246-260). Thousand Oaks, CA: Sage.

Boon, S. D., \& Sulsky, L. M. (1997). Attributions of blame and forgiveness in romantic relationships: A policy-capturing study. Journal of Social Behavior and Personality, 12, $19-44$.

Buchanan, G., \& Seligman, M.E. P. (Eds.) (1995). Explanatory style. Hillsdale, NJ: Erlbaum.

Darby, B.W., \& Schlenker, B.R. (1982). Children's reactions to apologies. Journal of Personality and Social Psychology, 43, 742-753.

Downey, G., Bonica, C., \& Rincon, C. (1999). Rejection sensitivity and adolescent romantic relationships. In The development of romantic relationships in adolescence (pp. 148-174). New York: Cambridge University Press.

Downey, G., \& Feldman, S.I. (1996). Implications of rejection sensitivity for intimate relationships. Journal of Personality and Social Psychology, 70, 1327-1343.

Downey, G.R., Feldman, S., \& Ayduk, O. (2000). Rejection sensitivity and male violence in romantic relationships. Personal Relationships, 7, 45-61.

Epstein, N. B., \& Baucom, D. H. (2002). enhanced cognitive-behavioral therapy for couples: A contextual approach. Washington, DC: American Psychological Association.

Fenell, D. (1993). Characteristics of long-term first marriages. Journal of Mental Health Counseling, 15, 446-460.

Fincham, F.D. (2000). The kiss of the porcupines: From attributing responsibility to forgiving. Personal Relationships, 7, 1-23.

Fincham, F.D., \& Beach, S.R. (2002a). Forgiveness in marriage: Implications for psychological aggression and constructive communication. Personal Relationships, 9, 239-251.

Fincham, F.D., \& Beach, S.R. (2002b). Forgiveness: Toward a public health approach to intervention. In J. H. Harvey \& A.E. Wenzel (Eds.), A clinician's guide to maintaining and enhancing close relationships (pp. 277-300). Hillsdale, NJ: Erlbaum.

Fincham, F.D., \& Bradbury, T.N. (1992). Assessing attributions in marriage: The Relationship Attribution Measure. Journal of Personality and Social Psychology, 62, 457-468.

Fincham, F.D., Paleari, G., \& Regalia, C. (2002). Forgiveness in marriage: The role of relationship quality, attributions and empathy. Personal Relationships, 9, 27-37.

Finkel, E. J., Rusbult, C. E., Kumashiro, M., \& Hannon, P. A. (2002). Dealing with betrayal in close relationships: Does commitment promote forgiveness? Journal of Personality and Social Psychology, 82, 956-974.

Jacobson, N. S., \& Christensen, A. (1998). Acceptance and change in couple therapy: A therapist's guide to transforming relationships. New York: Norton Press.

Johnson, S. M. (2000). The practice of emotionally focused marital therapy: Creating connection. New York: Brunner/Mazel.

Leary, M.R. (2001). Toward a conceptualization of interpersonal rejection. In M.R. Leary (Ed.), Interpersonal rejection (pp. 3-20). Oxford: Oxford University Press.

Levy, S.R., Ayduk, O., \& Downey, G. (2001). The role of rejection sensitivity in people's re- 
lationships with significant others and valued social groups. In M.R. Leary (Ed.), Interpersonal rejection (pp. 251-289). Oxford: Oxford University Press.

McCullough, M.E., Bellah, C.G., Kilpatrick, S.D., \& Johnson, J.L. (2001). Vengefulness: Relationships with forgiveness, rumination, well-being, and the Big Five. Personality and Social Psychology Bulletin, 27, 601-610.

McCullough, M.E, Pargament, K.I., \& Thoresen, C.E. (2000). The psychology of forgiveness: History, conceptual issues, and overview. In M.E. McCullough, K.I. Pargament, \& C.E. Thoresen (Eds.), Forgiveness: Theory, research, and practice (pp. 1-14). New York: Guilford.

McCullough, M.E., Rachal, K.C., Sandage, S.J., Worthington, E.L., Brown, S.W., \& Hight, T.L. (1998). Interpersonal forgiving in close relationships: II. Theoretical elaboration and measurement. Journal of Personality and Social Psychology, 75, 1586-1603.

McCullough, M.E., Worthington, E.L., Jr., \& Rachal, K.C. (1997). Interpersonal forgiving in close relationships. Journal of Personality and Social Psychology, 73, 321-336.

Ohbuchi, K., Kameda, M., \& Agarie, N. (1989). Apology as aggression control: Its role in mediating appraisal of and response to harm. Journal of Personality and Social Psychology, 56, 219-227.

Olson, D.H. (1977). Insiders' and outsiders' views of relationships: Research studies. In G.Levinger \& H.L. Raush (Eds.), Close relationships: Perspectives on the meaning of intimacy. Amherst: University of Massachusetts Press

Rosenthal, R. (1982). Conducting judgment studies. In P. Ekman \& K.R. Scherer (Eds.), Handbook of methods in nonverbal behavior research (pp. 187-261). New York: Cambridge University Press.

Sobel, M.E. (1988). Direct and indirect effects in linear structural equation models. In J.S. Long (Ed.), Common problems/proper solutions (pp. 46-64). Beverly Hills, CA: Sage.

Weiner, B., Frieze, I.H., Kukla, A., Reed, L., Rest, S., \& Rosenbaum, R.M. (1971). Perceiving the causes of successs and failure. Morristown, NJ: General Learning Presss.

Weiner, B., Graham, S., Peter, O., \& Zmuidinas, M. (1991). Public confession and forgiveness. Journal of Personality, 59, 281-312. 